\title{
Addendum
}

\section{A Practical Synthesis of (S)-Cyclopent-2-enol}

Monica G. Gonçalves-Martin, Andreas Saxer, Philippe Renaud* Synlett 2009, 2801.

In the original article, a major reference is missing. Alcohol $\mathbf{5}$ has been previously synthesized by Fürstner et al. according to the same synthetic pathway based on the Noyori's enantioselective transfer hydrogenation of the ynone $4 .^{1}$ We apologize for this omission and we thank Professor Alois Fürstner, MPI Mülheim, for drawing our attention to this oversight.

\section{Reference:}

(1) (a) Fürstner, A.; Aïssa, C.; Chevrier, C.; Teply, F.; Nevado, C.; Tremblay, M. Angew. Chem. Int. Ed. 2006, 45, 5832. (b) Fürstner, A.; Nevado, C.; Waser, M.; Tremblay, M.; Chevrier, C.; Teply, F.; Aïssa, C.; Moulin, E.; Müller, O. J. Am. Chem. Soc. 2007, 129, 9150. 